\title{
Co-Infection with COVID-19 and Malaria in a Young Man
}

\author{
Mustafa Mahmood Eid \\ Emergency Department, AI Ain Hospital, AI Ain, UAE
}

\section{Keywords}

Coronavirus · Malaria · Fever · Coronavirus disease 2019

\begin{abstract}
Malaria is an infectious disease caused by Plasmodium protozoa, which can be fatal if not diagnosed and treated promptly. COVID-19 is a newly emerging disease that can affect different body systems; however, the respiratory system is mainly reported. This case describes a 20-year-old man who presented with fever and joint pain and was found to have $P$. falciparum malaria in addition to a positive SARSCoV-2 test. The patient improved after he was treated with antimalarial medications in addition to supportive therapy. A co-infection of malaria and COVID-19 can occur. Thus, more studies need to be conducted on this co-infection. Besides, other diagnoses should be highly suspected in patients presenting with symptoms suggestive of SARS-CoV-2 infection, especially in vulnerable patients.
\end{abstract}

(C) 2021 The Author(s)

Published by S. Karger AG, Basel

\section{karger@karger.com www.karger.com/dmj \\ Karger $\stackrel{\text { ' }}{=}$}

GOPEN ACCESS

(c) 2021 The Author(s)

Published by S. Karger AG, Basel

This article is licensed under the Creative Commons AttributionNonCommercial-NoDerivatives 4.0 International License (CC BYNC-ND) (http://www.karger.com/Services/OpenAccessLicense) Usage and distribution for commercial purposes as well as any distribution of modified material requires written permission.

\section{Introduction}

Malaria is an infectious disease caused by Plasmodium protozoa, which is transmitted by a mosquito's bite. It is severe and can be a fatal illness if not diagnosed and appropriately managed. Different types of plasmodium exist; however, Plasmodium falciparum is the most dangerous one. Fortunately, early diagnosis and appropriate treatment carry an excellent prognosis. The affected patient typically develops paroxysm of fever, fatigue, malaise, and body ache $[1,2]$. SARS-CoV-2 is a new strain of coronavirus that started at the end of 2019 in China and spread worldwide [3]. The co-infection between malaria and COVID-19 is not understood or fully reported. In our case, the patient was found to have malaria with a positive SARS-CoV-2 test.

\section{Case Presentation}

A 20-year-old man presented to a healthcare facility complaining of intermittent fever and generalized body aches for 15 days. He denied any other complaints. His review of systems was negative. His examinations were unremarkable. Consequently, a set of blood tests, urinalysis, and chest X-ray were arranged. Moreover,

Mustafa Mahmood Eid

Emergency Department, Al Ain Hospital

Shakboot Bin Sultan Street

$\mathrm{Al}$ Ain 1006 (UAE)

dr.mustafa191982@gmail.com 
Table 1. Blood tests result of the patient

\begin{tabular}{ll}
\hline Blood tests & Results \\
\hline WBC & $5.0(4-11) \times 10^{9} / \mathrm{L}$ \\
Haemoglobin & $15.1(11.5-16.5) \mathrm{g} / \mathrm{dL}$ \\
Platelets & $133(140-440) \times 10^{9} / \mathrm{L}$ \\
C-reactive protein & $18(0-5) \mathrm{mg} / \mathrm{L}$ \\
Liver function test & Within normal limits \\
Urea and electrolytes & Within normal limits \\
PH & $7.25(7.35-7.45)$ \\
Lactate & $2.8(0.5-1.8)$ mmol/L \\
INR & 1.18 \\
Malaria thin film & Positive for malaria \\
Malaria thick film & Positive for malaria \\
Malaria parasite Ag & Plasmodium falciparum \\
D-dimer & $1.630(<500)$ mg/L \\
\hline
\end{tabular}

the SARS-CoV-2 nasopharyngeal swab was done and symptomatic management was commenced. His blood tests were unremarkable, apart from having a C-reactive protein of $28(0-5) \mathrm{mg} / \mathrm{L}$. At the same time, his chest radiograph and urinalysis were clear. Consequently, the patient improved and his fever subsided. $\mathrm{He}$ was discharged home on azithromycin and paracetamol. Two days later, the patient swab came positive for SARS-CoV-2, so he followed with a designated health facility for COVID-19. The patient was still complaining of fever spikes. Thus, the patient was sent to a quarantine facility on hydroxychloroquine, paracetamol, and multivitamins according to the hospital protocol and local authority guidelines. In the quarantine facility, the patient continued to report intermittent fever with headache and fatigue.

As a result, the patient was referred to the emergency department for further management. On presentation, the patient complained of fever and generalized fatigue. On further questioning, the patient gave a history of travel to his home country (Pakistan) before 5 months. He denied any upper or lower respiratory symptoms. The patient's vital signs were blood pressure of 129/68 mm $\mathrm{Hg}$, heart rate of 119 beats per min, the respiratory rate of 19 breaths per $\mathrm{min}$, the temperature of $38.9^{\circ} \mathrm{C}$, and oxygen saturation of $99 \%$ on room air. His chest was clear, with no abnormal heart sounds, and the abdomen was soft with no organomegaly. Therefore, blood tests, including malaria, SARS-CoV-2 nasopharyngeal swab, urinalysis, blood culture, and computerized tomography (CT) of the chest, were arranged. Additionally, paracetamol and intravenous fluid were commenced. His blood tests (Table 1) revealed P. falciparum malaria while his $\mathrm{CT}$ and urinalysis were clear. Therefore, the patient was admitted to the hospital. The patient was reviewed by the medical team, and the infectious disease consultant's opinion was requested. He was started on $20 \mathrm{mg}$ of artemether and $120 \mathrm{mg}$ of Lumefantrine. His blood culture showed no growth. The patient had an uneventful hospital admission; his malaria test came negative after 5 days of treatment and was asymptomatic. Nevertheless, 2 consecutive nasopharyngeal swabs for SARS-CoV-2 came positive. The patient was discharged from the hospital to a quarantine facility for further observation and follow-up. Later, his nasopharyngeal swab became negative and he was discharged home. The patient followed up with the internal medicine outpatient clinic 2 weeks later, and another visit after 5 weeks to follow-up on his condition. Furthermore, the patient was called later and he reported feeling fine with no complaints at all.

\section{Discussion}

Malaria continues to be one of the leading infectious diseases that significantly impact the health system with a potential fatality, especially in tropical areas. Malaria diagnosis in non-endemic areas needs a careful history with a level of suspicion, especially in suggestive findings in a patient examination or investigation [4].

Although COVID-19 initially started in China, it is now a widespread pandemic across the world. Patients infected with SARS-CoV-2 can have variable presentations ranging from asymptomatic to severe respiratory failure, though extra-pulmonary symptoms can present. However, fever, shortness of breath, throat pain, and coughing continue to be the most common symptoms [5]. The disease spreads mostly through respiratory droplets during close contact, although the ability to spread by airborne is still questionable [6]. Also, some studies have documented other ways of transmission, mainly extrapulmonary like fecal-oral [7].

Until now, there are no universal agreed guidelines for the treatment of COVID-19 disease. Nevertheless, several therapeutic regimens have been implanted. Of these, hydroxychloroquine, an antimalarial drug, has shown to have in vitro activity against the virus [8]. My hospital policy follows a regimen of hydroxychloroquine $400 \mathrm{mg}$ BID on day 1, then $200 \mathrm{mg}$ BID for 4 days, and an antiviral medication in severe cases or chest CT scan changes. All medications are given after the patient's consent.

To the best of my knowledge, no previous studies documented the co-infection of $P$. falciparum malaria and COVID-19. Moreover, the pathophysiology behind this is still unclear. Still, it is not known if SARS-CoV-2 infection reduced the immunity that led to a malaria flare-up or if malaria's complications increased the vulnerability to get COVID-19. In addition, it is not known whether antimalarial drugs ameliorate COVID-19 symptoms or mask them.

\section{Conclusion}

Physicians should highly suspect other diseases and diagnoses in patients presenting with symptoms suggestive of SARS-CoV-2 infection, especially in vulnerable 
patients. In addition, physicians should always bear in mind the possibility of a combination of COVID-19 and other diseases. Besides, more studies need to be conducted to understand the pathophysiology and any clinical significance of this co-infection.

\section{Statement of Ethics}

Written informed consent was obtained from the patient for publication of this case report.

\section{Conflict of Interest Statement}

The author has no conflicts of interest.

\section{Funding Sources}

I have no funding or support to declare.

\section{Author Contributions}

The author declares that he solely participated in the design, execution, and the writing of this case.

\section{References}

1 Malaria Fact Sheet. No. 94. Updated 2014 Mar: World [Internet]. Relief Web. 2020. Available from: https://reliefweb.int/report/ world/malaria-fact-sheet-no-94-updatedmarch-2014.

2 Caraballo H, King K. Emergency department management of mosquito-borne illness: malaria, dengue, and west nile virus. Emerg Med Pract. 2014;16(5):1-23.

3 Eid M, Al-Kaisy M, Regeia W, Jiwa Khan $\mathrm{H}$. The prognostic accuracy of neutrophil-lymphocyte ratio in COVID-19 patients. Front Emerg Med. 2021;5(1):e8.
4 Nadjm B, Behrens RH. Malaria: an update for physicians. Infect Dis Clin North Am. 2012; 26(2):243-59.

5 Coronavirus disease 2019 (COVID-19): symptoms [Internet]. Atlanta, GA: Centers for Disease Control and Prevention; 2020. Available from: https://www.cdc.gov/ coronavirus/2019-ncov/symptoms-testing/ symptoms.html.

6 Transmission of SARS-CoV-2: implications for infection prevention precautions [Internet]. Who Int. 2020. Available from: https:// www.who.int/publications/i/item/modes-of- transmission-of-virus-causing-covid-19-implications-for-ipc-precaution-recommendations.

7 Gu J, Han B, Wang J. COVID-19: gastrointestinal manifestations and potential fecal: oral transmission. Gastroenterology. 2020;158(6): 1518-9.

8 Colson P, Rolain JM, Lagier JC, Brouqui P, Raoult D. Chloroquine and hydroxychloroquine as available weapons to fight COVID-19. Int J Antimicrob Agents. 2020;55(4): 105932. 